\title{
Mild Bronchopulmonary Dysplasia
}

National Cancer Institute

\section{Source}

National Cancer Institute. Mild Bronchopulmonary Dysplasia. NCI Thesaurus. Code C119756.

A chronic lung disorder associated with pulmonary maldevelopment, scarring, and/or inflammation that develops in preterm neonates exposed to supplemental oxyg en for at least 28 days. For infants born before 32 weeks gestation with mild BPD, there is no supplemental oxygen requirement at 36 weeks postmenstrual age or earlier discharge. For infants born after 32 weeks with mild BPD, there is no supplemental oxygen requirement at 56 days post-natal age or at earlier discharge. 